\title{
Dinâmica temporal da umidade do solo em uma bacia hidrográfica no semiárido Pernambucano
}

\section{Temporal dynamics of soil moisture in a watershed in the Pernambuco semiarid region.}

\author{
Rogério Oliveira de Melo $^{1}$ e Abelardo Antônio de Assunção Montenegro ${ }^{2}$
}

${ }^{1}$ Instituto Federal de Educação Ciência e Tecnologia de Pernambuco, PE, Brasil

rogerio.melo@garanhuns.ifpe.edu.br

${ }^{2}$ Universidade Federal Rural de Pernambuco, Recife PE, Brasil

abelardo.montenegro@yahoo.com.br

Recebido: 25/03/14 - Revisado: 08/07/14 - Aceito: 14/11/14

\begin{abstract}
RESUMO
Este trabalho teve como objetivo avaliar o comportamento temporal da umidade do solo em uma bacia hidrográfica experimental localizada no município de Pesqueira, região do semiárido Pernambucano. Os registros de umidade foram obtidos utilizando uma sonda de nêutrons, nas profundidades 0,0 - 0,2 m e 0,2 - 0,4 m, entre outubro de 2010 e dezembro de 2011. O monitoramento foi realizado em 18 pontos dabacia, distribuidos em locais de Caatinga Natural e áreas de Pasto na condição de sequeiro, em diferentes unidades de solo separados em ao ponto médio da bacia, considerando seu comprimento axial, compondo quatro tratamentos descritos por Caatinga Natural a Montante - CNM e a Jusante - CNJ e Pasto a Montante - PM e a Jusante - PJ. Os dados foram submetidos à análise estatística descritiva. Foi possível verificar que áreas localizadas no Argissolo Amarelo (CNM e PM) apresentam valores de umidade maiores em função da sua maior capacidade de retenção. Porém, os tratamentos CNJ e PJ, situados em solos do tipo Neossolo Regolítico e Litólico, apresentam maiores incrementos de umidade por ocorrência dos eventos de chuva. Observa-se ainda uma elevada variabilidade temporal da umidade, pouco influenciada pelos diferentes tratamentos, sendo a variabilidade entre os valores médios da umidade do solo para as condicõoes avaliadas, menor durante o período das chuvas, bem como na profundidade 0,2 - 0,4m.
\end{abstract}

Palavras Chave: Variabilidade da Umidade. Sonda de Nêutrons. Caatinga

\begin{abstract}
This study aimed to evaluate the temporal behavior of soil moisture in an experimental watershed located in Pesqueira, Pernambuco semiarid region. Soil moisture was determined using a neutron probe at depths from 0.0 - 0.2 and 0.2 - 0.4 m, between October 2010 and December 2011. Monitoring was conducted at 18 points in the watershed, distributed at locations with Natural Caatinga and in areas of upland pasture, classified according to its location with respect to the midpoint of the basin, considering its axial length, comprising four treatments described as the Caatinga upstream - CNM and Downstream - CNJ, and Pasture upstream - PM and Downstream - PJ. Data was submitted to descriptive statistical analysis. It has been noticed that areas located in the Yellow Argisol (CNM and PM) have higher moisture values due to their higher retention capacity. However, PJ and CNJ, located in Regolitic Neosol and Litholic soil types, showed higher moisture increments due to rainfall events. There is equally a high temporal variability of moisture, little influenced by the different treatments, the variability between the mean values of soil moisture for the evaluated conditions, lower during the rainy period, and at the depth of $0.2-0.4 m$.
\end{abstract}

Keywords: Variability of humidity. Neutron Probe. Caatinga 


\section{INTRODUÇÃO}

O entendimento do comportamento hidrológico de bacias hidrográficas depende da disponibilidade de dados, e da manutenção de redes de monitoramento. Em regiões semiáridas, os processos hidrológicos são mais complexos, requerendo medições contínuas de forma a representar eventos climatológicos não frequentes (MONTE-MOR et al., 2012).

A umidade no solo constitui-se em uma das variáveis mais importantes para estudos de condutividade hidráulica e infiltração (ROSSATO; ALVALÁ; TOMASELLA, 2004). O conteúdo de água no solo é influenciado por um conjunto de fatores, dentre os quais se destacam a heterogeneidade nas características do solo, tais como textura, conteúdo de matéria orgânica, estrutura e existência de macroporosidade, que afetam a transmissividade do fluido e as propriedades de retenção da água no solo; o declive, por afetar o escoamento superficial e a infiltração, e ainda o tipo e a densidade da cobertura vegetal, os quais interferem no volume de água, através de mecanismos de evapotranspiração, radiação solar e outros fatores meteorológicos (GÓMEZ-PLAZA et al., 2000; ILLSTON; BASARA; CRAWFORD, 2004; MEDEIROS, 2004; MEDEIROS; CLARKE, 2007; QIU et al., 2001). Da variedade de feições topográficas de um terreno resultam diferenças no aporte de energia solar que fazem da topografia e da orientação de vertentes fatores importantes na determinação de características ecohidrológicas (TAKYU; AIBA; KITAYAMA, 2002). Tendo o conhecimento de quais vertentes recebem mais radiação solar é possível apontar os locais de maior umidade, ajudando assim no entendimento da dinâmica hidrológica nesses pontos (YANG et al., 2012). Para Robinson et al. (2008), a topografia e a posição do declive são dominantes durante os períodos úmidos, enquanto os aspectos da vegetação, da textura do solo e da sua estrutura vertical são mais importantes nos períodos secos. Joshi et al. (2011) destacam que os principais aspectos topográficos que influenciam na variabilidade da umidade do solo são a elevação, a declividade e a curvatura da superfície.

A umidade do solo possui alta variabilidade no espaço e no tempo, em face da influência de diversos processos estáticos e dinâmicos no solo, além da interferência das mudanças sazonais no regime de chuvas. Nesse aspecto, é relativamente complexo descrever os processos ou fatores dominantes que podem influenciar na variabilidade espaço-temporal da umidade do solo, devido à heterogeneidade e à diversidade das condições ambientais envolvidas (ÁVILA et al., 2011). Para Santos (2010), é difícil identificar a importância relativa destes fatores devido a suas mútuas e múltiplas influências na umidade do solo. Consequentemente, o entendimento da relação entre umidade do solo e os fatores mencionados necessitam de estudos em vários locais e em diferentes escalas, em particular em bacias experimentais. Neste contexto, a identificação de locações representativas do comportamento médio da umidade do solo é de relevância (HU; SI, 2014). Vereecken et al. (2014) apresentam ampla discussão do estado da arte tanto com relação a técnicas de medição de umidade, como discutem metodologias para análises estatísticas de variabilidade, no tempo e no espaço.

Trabalhos apontam o uso do solo como um dos prin- cipais fatores que controlam a umidade (PAN et al., 2008; QIU et al., 2010;). Santos, Silva e Montenegro (2010) observaram que a umidade do solo no semiárido apresentou elevada variabilidade no tempo, estando relacionada aos diferentes tipos de cobertura e propriedades do solo, sendo mais dependente da intensidade de precipitação do que do total precipitado, bem como da umidade antecedente.

Segundo Wilcox et al. (2012), em áreas de desertos quentes, a substituição da vegetação nativa por gramíneas não nativas usualmente provoca redução no escoamento superficial e tem pequeno efeito na evapotranspiração. Montenegro e Ragab (2010), trabalhando com simulação de respostas hidrológicas aos diferentes usos do solo em uma bacia hidrográfica do semiárido brasileiro, observaram que a substituição da vegetação nativa do tipo Caatinga pelo cultivo de mamona, proporcionaria aumento na recarga dos aquíferos e nas vazões, principalmente devido à redução da interceptação e evapotranspiração.

O objetivo desse trabalho foi investigar a variabilidade temporal da umidade do solo na superficie e subsuperficie, sobcondições de cobertura vegetal de caatinga e pasto, em uma bacia experimental na região do semiárido pernambucano, utilizando sonda de nêutrons.

\section{MATERIAL E MÉTODOS}

\section{Localização e características da área de estudo}

O estudo foi realizado na Bacia Experimental do Jatobá, município de Pesqueira, região de Agreste do Estado de Pernambuco, situada entre as coordenadas $8^{\circ} 34^{\prime} 17^{\prime \prime}$ e $8^{\circ} 18^{\prime} 11^{\prime \prime}$

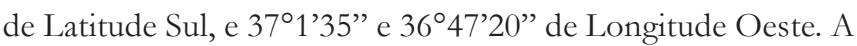
microbacia possui uma área de $12,44 \mathrm{~km}^{2}$ e um perímetro de $16 \mathrm{~km}$. O rio principal possui $6,5 \mathrm{~km}$ de extensão.

A precipitação média anual na região é de $607 \mathrm{~mm}$, com temperatura média de $23^{\circ} \mathrm{C}$ e evapotranspiração potencial anual de cerca de $2.000 \mathrm{~mm}$ (SANTOS et al., 2008). A vegetação predominante é a caatinga hipoxerófila, cactáceas e bromeliáceas. As unidades pedológicas encontradas na área da bacia são Argissolo Amarelo na porção mais à montante; Neossolo Litólico nas encostas circundantes, e Neossolo Regolítico na porção à jusante da bacia (CÔRREA; RIBEIRO, 2001).

\section{Monitoramento}

\section{Precipitação}

$\mathrm{Na}$ bacia experimental há três pluviômetros automáticos, com discretização horária (Figura 1). A rede de monitoramento também dispõe de um pluviômetro Ville de Paris.Considerando a variabilidade espacial da distribuição das chuvas, as informações de precipitação consideradas para cada porção da bacia hidrográfica foram obtidas através da análise dos registros de cada um dos dois pluviômetros localizados a montante e a jusante do ponto médio. Além da análise isolada da distribuição das precipitações dentro da área da bacia, essas informações foram utilizadas na investigação do comportamento da umidade do solo. 


\section{Umidade do solo}

A umidade do solo foi monitorada utilizando-se uma sonda de nêutrons - SN, tipo 503 DR HYDROPROBE® (Figura 1) calibrada para cada ponto e profundidades avaliadas. Os tubos de acesso, em PVC, foram instalados compondo uma rede de monitoramento com 18 locais de medição. O tempo de contagem utilizado nas medições com a SN foi de 30 segundos, de acordo com o recomendado por Andrade et al. (2001). A sonda de nêutrons apresenta elevada confiabilidade de leitura e baixa incerteza, devido à escala de medição (área de influência), e a não existência de interferência da salinidade da água nas leituras.

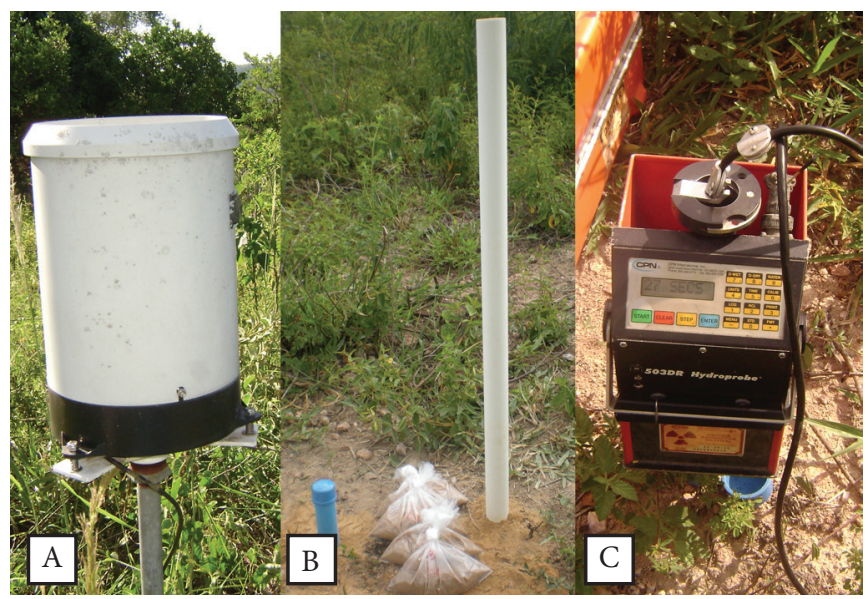

Figura 1- Pluviômetro automático instalado na área da bacia do Jatobá (A); Tubo de acesso para sonda de Nêutrons (B); Monitoramento da umidade do solo utilizando sonda de nêutrons (C)

As medições de umidade volumétrica analisados foram realizadas nas profundidades $0,0-0,2 \mathrm{~m}$ e 0,2-0,4 $\mathrm{m}$, em locais com presença de Caatinga Natural - CN e Pasto - P (Figura 2).

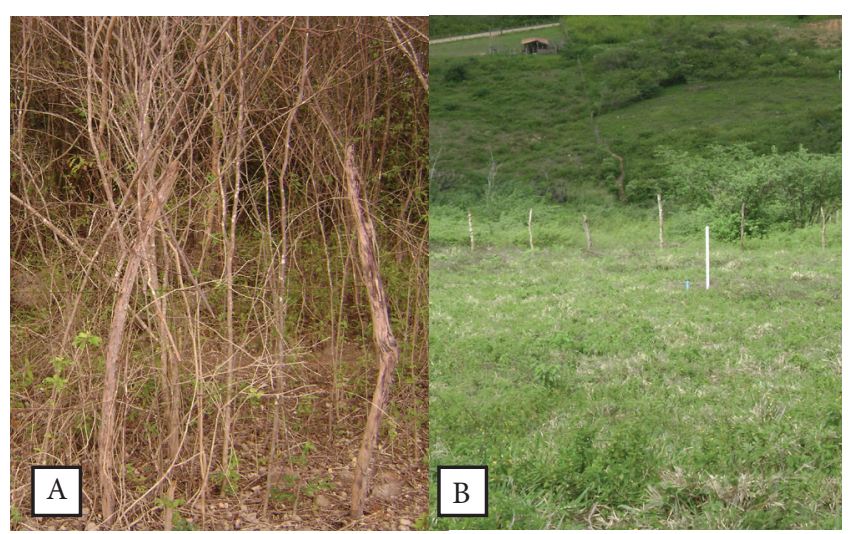

Figura 2 - Área com Caatinga Natural (A) e Pasto (B), monitoradas na bacia hidrográfica do riacho Jatobá

Agrupou-se aslocações em função da localização que ocupam dentro da bacia hidrográfica, mediante consideração de pontos a montante e jusante em relação ao ponto médio do comprimento axial. Essa divisão permitiu separar os pontos também por tipos de solos diferentes, sendo predominante a presença do Argissolo Amarelo a montante da Bacia e dos Neossolos Litólicos e Regolíticos na porção a jusante (Figura 3). Dessa forma, os tratamentos obtidos são Caatinga Natural a
Montante - CNM e a Jusante - CNJ, e Pasto a Montante - PM e a Jusante - PJ na bacia.

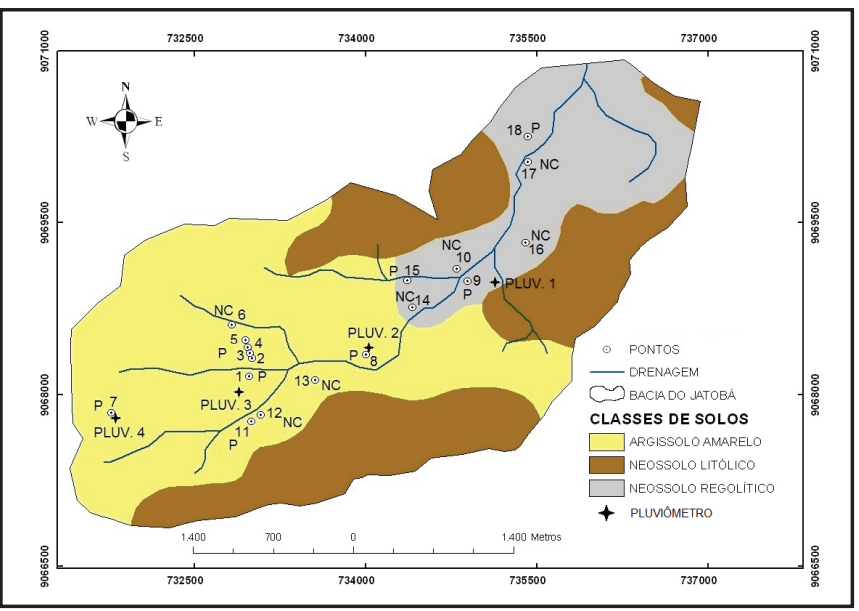

Figura 3 - Mapa de solos da bacia hidrográfica do Jatobá com a localização dos pontos de monitoramento

O intervalo de tempo entre os monitoramentos da umidade do solo foi quinzenal durante o período de ocorrência de chuvas (maio a julho), com vista a obter um monitoramento mais detalhado neste período, e mensal para os períodos de estiagem (agosto a abril). Os resultados obtidos nesse trabalho são baseados no monitoramento realizado entre outubro de 2010 à dezembro de 2011 (total de 16 medições).

Os atributos físicos do solo nos pontos de monitoramento foram determinados segundo os métodos descritos pela EMBRAPA (1997), para as camadas de 0,0 - 0,2 m e 0,2 - 0,4 m.

\section{Orientação de vertentes}

O mapa de orientação de vertentes permite inferir quais delas recebem maior insolação. Para obter uma representação do relevo, foi gerado um modelo digital de elevação do terreno (MDE) a partir de imagens SRTM, com resolução espacial de 90 m. A partir do MDE foi gerado o mapa matricial, com o valor da orientação em graus representada por pixel (em relação ao norte geográfico). Todos os procedimentos foram realizados utilizando-se o software ArcGis 9. 3.

Com a localização dos pontos de monitoramento dentro da matriz de vertentes, esses foram agrupados de forma a representar uma mesma condição de cobertura vegetal, porém em posições distintas com relação à vertente, sendo,portanto,considerado para essa análise a comparação entre os pontos sob condição de cobertura vegetal do tipo Caatinga Natural localizadas nas vertentes ao Sul - CNS e ao Norte - CNN, e Pasto ao Sul - PS e Norte PN.

\section{Análises}

\section{Estatística}

Foi realizada análise estatística descritiva, através da avaliação de medidas de tendência central (média, mediana e moda) e dispersão (desvio padrão, variância e coeficiente de 
variação). Para comparação entre as médiasdos tratamentos, adotou-se o teste de Tukey ao nível de significância de 5\%. O programa utilizado foi o Assistência Estatística - ASSISTAT 7.6.

\section{Efetividade da água do solo}

Para realizar uma avaliação efetiva sobre a umidade do solo nos pontos de monitoramento, foi calculada a efetividade da água no solo (SWE), utilizando a Equação 1, proposta por Porporato et al. (2002), e utilizada por Santos et al. (2011).

$$
S W_{E}=\frac{S_{A}-S_{P M P}}{S_{C C}-S_{P M P}}(1)
$$

em que SAé a umidade atual do solo; SCCé a umidade do solo na capacidade de campo e SPMPé a umidade do solo no ponto de murcha permanente. A efetividade da umidade do solo pode ser classificada em cinco grupos (Tabela 1), de acordo com Chen et al. (2007).

Tabela 1 - Critério para avaliação da efetividade da água no solo

\begin{tabular}{cc}
\hline $\mathbf{S W}_{\mathbf{E}}$ & Efetividade \\
\hline$>1,00$ & Extremamente Efetivo \\
$0,75-1,00$ & Alta efetividade \\
$0,50-0,75$ & Moderada-alta efetividade \\
$0,25-0,50$ & Baixa efetividade \\
$0,00-0,25$ & Efetividade marginal \\
$<0,00$ & Não efetivo \\
\hline
\end{tabular}

Fonte: Chen et al. (2007)

\section{RESULTADOS E DISCUSSÃO}

A figura 4 mostra a distribuição temporal das chuvas ocorridas durante o período de monitoramento. $\mathrm{O}$ total de chuvas registrado foi de $1.183,2 \mathrm{~mm}$ para a porção a montante da bacia e 1.002,0 mm para a porção a jusante do ponto médio. Os meses com maior precipitação foram janeiro, maio e junho, enquanto novembro e dezembro de 2010 apresentaram os menores totais pluviométricos, para ambos locais monitorados.

Comparando o comportamento da distribuição das

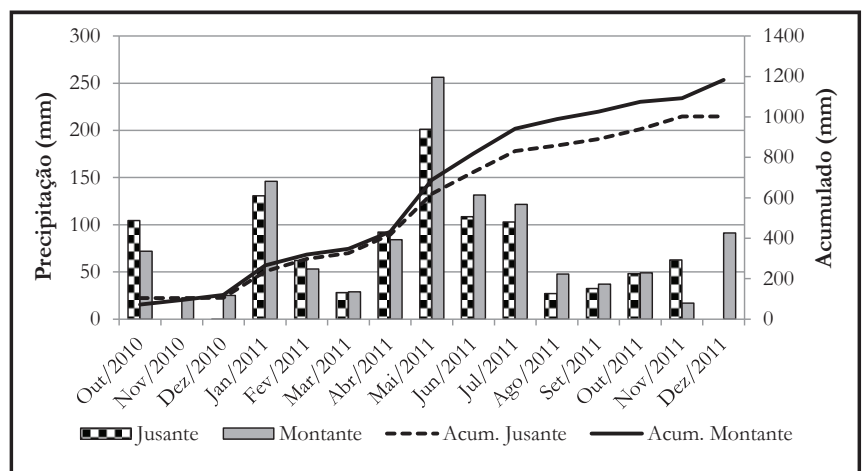

Figura 4 - Distribuição temporal da precipitação na bacia do Jatobá no período de outubro/2010 a dezembro/2011, considerando a ocorrência na porção a montante e a jusante do ponto médio da bacia precipitações com os dados históricos apresentados por Silva, Montenegro e Moura (2008), foi possível verificar que apenas fevereiro e março de 2011 apontaram registros mensais abaixo da média histórica, calculada entre os anos de 1961 a 2007, que é de 70,0 e 105,0 mm para esses meses, respectivamente. Esse comportamento é consequência da estiagem atípica que ocorreu durante o período de estudo.

A distribuição das precipitações dos demais meses foi semelhante aos dados históricos, porém com maiores valores totais registrados.

A umidade do solo sob as quatro condições avaliadas (Tabela 2) nas áreas localizadas a montante do ponto médio da bacia apresentam valores médios mais elevados. Além da maior precipitação registrada durante o período experimental, os pontos de monitoramento localizados nessa área estão situados em Argissolo Amarelo e apresentam maiores teores de argila que o Neossolo. Tal condição é esperada pelo fato de solos com predominância dessa fração possuírem maior porcentagem de material coloidal, maior espaço poroso e superfície adsortiva maior que os solos de textura mais arenosa (CARLESSO; ZIMMERMANN, 2000).A análise textural dos solos nos pontos de monitoramento da bacia mostra teores de areia variando de 495,8 a 784,0 g Kg-1 e argila entre 88,8 e 292,0 g Kg-1 para a camada de $0,0-0,2 \mathrm{~m}$ de profundidade. Para a profundidade de $0,2-0,4 \mathrm{~m}$ foram verificados teores de areia entre 436,2 a 834,0 g Kg-1 e argila de 82,4 a 392,0 g Kg-1 (Tabela 3).

Ainda é possível verificar que a umidade do solo apresenta valores médios maiores na área de pasto, principalmente quando ocorreu precipitação acumulada antecedente, o que reflete a interceptação das precipitações, causada pelo padrão da vegetação, e sua interferência na umidade do solo, principalmente nas camadas superficiais. Pan et al. (2008), estudando a variabilidade espacial do conteúdo de água da superfície do solo em uma região árida da China, verificaram que a vegetação influenciou significativamente na variabilidade da umidade do solo, pelo padrão de precipitação imposto pelo dossel, devido à interceptação vegetal. Há ainda uma tendência da umidade nas áreas de pasto diminuir mais rapidamente nos períodos sem chuvas, o que indica que na camada superficial há uma maior demanda dessa vegetação pela umidade do solo, além da maior exposição favorecer a evaporação. Tinley (1982) relata que essa dinâmica temporal é especialmente pronunciada em ecossistemas com limitada disponibilidade hídrica, como no semiárido. Isto pode ser atribuído à diferença de transpiração das plantas em diferentes períodos.

Avaliando o comportamento temporal dos registros, no início do monitoramento, verificou-se que a umidade do solo, na camada superficial, encontrava-se abaixo do ponto de murcha permanente para todos os tratamentos. Para o monitoramento seguinte, realizado no dia $05 / 11 / 10$, foi registrada uma precipitação acumulada nos 15 dias anteriores de 72 e 104,7 mm nas duas porções da bacia, que foi suficiente para elevar e manter a umidade do solo em valores superiores ao ponto de murcha permanente, mesmo sem ocorrência de chuvas nos 7 dias antecedentes ao monitoramento. Percebe-se que o incremento na umidade foi maior para as áreas a jusante, onde houve $32,7 \mathrm{~mm}$ de chuva a mais, com uma elevação da umidade em 142,4\% e 
Melo e Montenegro.: Dinâmica temporal da umidade do solo em uma bacia hidrográfica no semiárido Pernambucano

Tabela 2 - Valores médios da umidade volumétrica do solo na bacia do Jatobá, nas diferentes condições de superfície avaliadas, durante o período de monitoramento nas profundidades $0,0-0,2 \mathrm{~m}$ e $0,2-0,4 \mathrm{~m}$

\begin{tabular}{|c|c|c|c|c|c|c|c|c|c|}
\hline \multirow{3}{*}{$\begin{array}{c}\text { Prof. } \\
\text { m }\end{array}$} & \multirow{3}{*}{ Data } & \multicolumn{4}{|c|}{ Umidade volumétrica } & \multicolumn{4}{|c|}{ Chuva antecedente (mm) } \\
\hline & & $\mathrm{CNM}$ & PM & $\mathrm{CNI}$ & PI & \multicolumn{2}{|c|}{ Montante } & \multicolumn{2}{|c|}{ Jusante } \\
\hline & & \multicolumn{4}{|c|}{----------------- $\mathrm{cm}^{3} \mathrm{~cm}^{-3}$} & 7 dias & 15 dias & 7 dias & 15 dias \\
\hline \multirow[t]{16}{*}{$0,0-0,2$} & $07 / 10 / 10$ & $0,071 \mathrm{a}$ & $0,069 \mathrm{a}$ & $0,038 \mathrm{a}$ & $0,035 \mathrm{a}$ & 0,0 & 3,6 & 0,0 & 2,0 \\
\hline & $05 / 11 / 10$ & 0,118 a & $0,098 \mathrm{~b}$ & $0,092 \mathrm{bc}$ & $0,080 \mathrm{c}$ & 0,0 & 72,0 & 0,0 & 104,7 \\
\hline & $17 / 12 / 10$ & $0,064 \mathrm{ab}$ & $0,072 \mathrm{a}$ & $0,039 \mathrm{~b}$ & $0,039 \mathrm{~b}$ & 1,0 & 13,0 & 0,0 & 0,0 \\
\hline & $24 / 01 / 11$ & 0,153 a & $0,180 \mathrm{a}$ & $0,148 \mathrm{a}$ & $0,160 \mathrm{a}$ & 97,0 & 103,0 & 84,6 & 91,4 \\
\hline & 04/02/11 & $0,133 \mathrm{ab}$ & $0,138 \mathrm{a}$ & $0,076 \mathrm{c}$ & $0,087 \mathrm{bc}$ & 27,0 & 140,0 & 21,3 & 123,5 \\
\hline & $22 / 02 / 11$ & $0,107 \mathrm{a}$ & $0,131 \mathrm{a}$ & $0,084 \mathrm{a}$ & 0,083 a & 17,0 & 35,0 & 20,3 & 34,0 \\
\hline & $28 / 03 / 11$ & $0,059 \mathrm{a}$ & $0,052 \mathrm{a}$ & $0,033 \mathrm{a}$ & $0,034 \mathrm{a}$ & 0,0 & 6,0 & 0,0 & 8,9 \\
\hline & $25 / 04 / 11$ & $0,81 \mathrm{ab}$ & $0,095 \mathrm{a}$ & $0,048 \mathrm{~b}$ & $0,061 \mathrm{ab}$ & 8,0 & 38,0 & 14,2 & 42,2 \\
\hline & $15 / 05 / 11$ & $0,169 \mathrm{a}$ & $0,165 \mathrm{a}$ & $0,123 \mathrm{a}$ & 0,136 a & 22,9 & 98,3 & 23,6 & 98,3 \\
\hline & $02 / 07 / 11$ & $0,183 \mathrm{a}$ & $0,174 \mathrm{a}$ & $0,131 \mathrm{~b}$ & $0,147 \mathrm{ab}$ & 11,9 & 57,4 & 6,1 & 50,0 \\
\hline & $28 / 07 / 11$ & $0,208 \mathrm{ab}$ & $0,211 \mathrm{a}$ & $0,078 \mathrm{c}$ & $0,127 \mathrm{bc}$ & 14,0 & 59,0 & 13,0 & 44,7 \\
\hline & $25 / 08 / 11$ & $0,114 \mathrm{ab}$ & $0,120 \mathrm{a}$ & $0,042 \mathrm{c}$ & $0,074 \mathrm{bc}$ & 18,0 & 25,0 & 9,4 & 16,0 \\
\hline & $06 / 10 / 11$ & $0,054 \mathrm{a}$ & $0,056 \mathrm{a}$ & $0,026 \mathrm{a}$ & $0,035 \mathrm{a}$ & 0,0 & 1,0 & 0,0 & 1,5 \\
\hline & 03/11/11 & $0,049 \mathrm{a}$ & $0,044 \mathrm{a}$ & $0,054 \mathrm{a}$ & 0,035 a & 1,0 & 6,0 & 12,2 & 40,9 \\
\hline & $06 / 12 / 11$ & $0,044 \mathrm{a}$ & $0,039 \mathrm{a}$ & $0,023 \mathrm{a}$ & $0,019 \mathrm{a}$ & 0,0 & 0,0 & 0,0 & 0,0 \\
\hline & $28 / 12 / 11$ & $0,035 \mathrm{ab}$ & $0,049 \mathrm{a}$ & $0,019 \mathrm{~b}$ & $0,013 \mathrm{~b}$ & 0,0 & 0,0 & 0,0 & 0,0 \\
\hline$C V(\%)$ & & 52,8 & 52,5 & 61,4 & 65,2 & & & & \\
\hline \multirow[t]{16}{*}{$0,2-0,4$} & $07 / 10 / 10$ & $0,070 \mathrm{a}$ & $0,084 \mathrm{a}$ & $0,046 \mathrm{a}$ & $0,055 \mathrm{a}$ & 0,0 & 3,6 & 0,0 & 2,0 \\
\hline & $05 / 11 / 10$ & $0,156 \mathrm{a}$ & $0,132 \mathrm{a}$ & $0,133 \mathrm{a}$ & $0,127 \mathrm{a}$ & 0,0 & 72,0 & 0,0 & 104,7 \\
\hline & $17 / 12 / 10$ & $0,076 \mathrm{a}$ & $0,080 \mathrm{a}$ & $0,055 \mathrm{a}$ & 0,064 a & 1,0 & 13,0 & 0,0 & 0,0 \\
\hline & $24 / 01 / 11$ & $0,145 \mathrm{ab}$ & $0,196 \mathrm{a}$ & $0,109 \mathrm{~b}$ & $0,108 \mathrm{~b}$ & 97,0 & 103,0 & 84,6 & 91,4 \\
\hline & 04/02/11 & $0,146 \mathrm{ab}$ & $0,176 \mathrm{a}$ & $0,084 \mathrm{~b}$ & $0,097 \mathrm{~b}$ & 27,0 & 140,0 & 21,3 & 123,5 \\
\hline & $22 / 02 / 11$ & $0,102 \mathrm{ab}$ & $0,133 \mathrm{a}$ & $0,076 \mathrm{~b}$ & $0,072 \mathrm{~b}$ & 17,0 & 35,0 & 20,3 & 34,0 \\
\hline & $28 / 03 / 11$ & $0,069 \mathrm{a}$ & $0,090 \mathrm{a}$ & $0,052 \mathrm{a}$ & $0,060 \mathrm{a}$ & 0,0 & 6,0 & 0,0 & 8,9 \\
\hline & $25 / 04 / 11$ & $0,080 \mathrm{ab}$ & $0,106 \mathrm{a}$ & $0,053 \mathrm{~b}$ & $0,063 \mathrm{ab}$ & 8,0 & 38,0 & 14,2 & 42,2 \\
\hline & $15 / 05 / 11$ & 0,166 a & $0,174 \mathrm{a}$ & $0,121 \mathrm{a}$ & $0,150 \mathrm{a}$ & 22,9 & 98,3 & 23,6 & 98,3 \\
\hline & $02 / 07 / 11$ & $0,172 \mathrm{a}$ & $0,184 \mathrm{a}$ & 0,129 a & $0,156 \mathrm{a}$ & 11,9 & 57,4 & 6,1 & 50,0 \\
\hline & $28 / 07 / 11$ & $0,251 \mathrm{a}$ & $0,182 \mathrm{ab}$ & $0,103 \mathrm{~b}$ & $0,127 \mathrm{~b}$ & 14,0 & 59,0 & 13,0 & 44,7 \\
\hline & $25 / 08 / 11$ & $0,123 \mathrm{ab}$ & $0,127 \mathrm{a}$ & $0,048 \mathrm{~b}$ & $0,078 \mathrm{ab}$ & 18,0 & 25,0 & 9,4 & 16,0 \\
\hline & $06 / 10 / 11$ & $0,060 \mathrm{a}$ & $0,083 \mathrm{a}$ & $0,047 \mathrm{a}$ & $0,048 \mathrm{a}$ & 0,0 & 1,0 & 0,0 & 1,5 \\
\hline & $03 / 11 / 11$ & $0,054 \mathrm{a}$ & $0,066 \mathrm{a}$ & $0,064 \mathrm{a}$ & $0,055 \mathrm{a}$ & 1,0 & 6,0 & 12,2 & 40,9 \\
\hline & $06 / 12 / 11$ & $0,054 \mathrm{a}$ & $0,065 \mathrm{a}$ & $0,048 \mathrm{a}$ & $0,034 \mathrm{a}$ & 0,0 & 0,0 & 0,0 & 0,0 \\
\hline & $28 / 12 / 11$ & $0,048 \mathrm{a}$ & $0,063 \mathrm{a}$ & $0,044 \mathrm{a}$ & $0,028 \mathrm{a}$ & 0,0 & 0,0 & 0,0 & 0,0 \\
\hline$C V(\%)$ & & 52,0 & 39,6 & 42,8 & 48,4 & & & & \\
\hline
\end{tabular}

Médias seguidas de letras minúsculas na mesma coluna, não diferem entre si, a nível de 5\% de significância, pelo teste de Tukey. CNM - Caatinga Natural à Montante; PM - Pasto à Montante; CNJ - Caatinga Natural à Jusante e PJ - Pasto à Jusante.

127,8\% para as áreas de CN e P, respectivamente.

Para o monitoramento realizado no dia 24/01/11, houve uma precipitação acumulada de 103,0 e 91,4 mm nos 15 dias antecedentes na área a montante e a jusante, respectivamente, porém, com a maior parte acontecendo nos 7 dias anteriores ao monitoramento ( $94 \%$ e $92 \%$ dos totais registrados), elevando a umidade do solo que novamente encontrava-se a níveis abaixo do PMP, com aumentos de 139,1\% em CNM e 150\% para PM; e $279,5 \%$ na área de CNJ e 310,3\% em PJ. Embora as maiores precipitações acumuladas (7 dias antecedentes) tenham sido registradas para o monitoramento realizado no dia 24/01/2011, essa foi suficiente para elevar a umidade do solo aos maiores valores encontrados durante todo o período experimental apenas na área a jusante do ponto médio da bacia (na profundidade de $0,0-0,2 \mathrm{~m}$ ). Essa condição só foi encontrada para os tratamentos a montante (em ambas as profundidades) no dia 28/07/2011, mesmo com precipitações acumuladas inferiores às já registradas anteriormente. Esse comportamento é função das características distintas dos tipos de solos predominantes em cada porção da bacia e suas influências na infiltração e retenção da água.

Nas áreas de CNJ e PJ, onde há predominância de Neossolos Regolítico e Litólico, uma maior parte da lâmina total precipitada nos dias anteriores à 24/01/2011 (84,6 mm para os 7 dias) infiltrou, contribuindo com a elevação da umidade nessas áreas, as quais atingiram o valor máximo registrado durante todo período experimental. Embora para essa mesma data, a precipitação acumulada nas áreas de CNM e PM tenham sido maiores (97,0 mm), por ser o Argissolo Amarelo o tipo de solo predominante, menos favorável à infiltração, verificou-se que essa porção da bacia não atingiu os maiores registros para umidade nessa data. Observa-se, também, que a umidade máxima para a profundidade de $0,2-0,4 \mathrm{~m}$ nas áreas $\mathrm{CNJ}$ e PJ só foi 


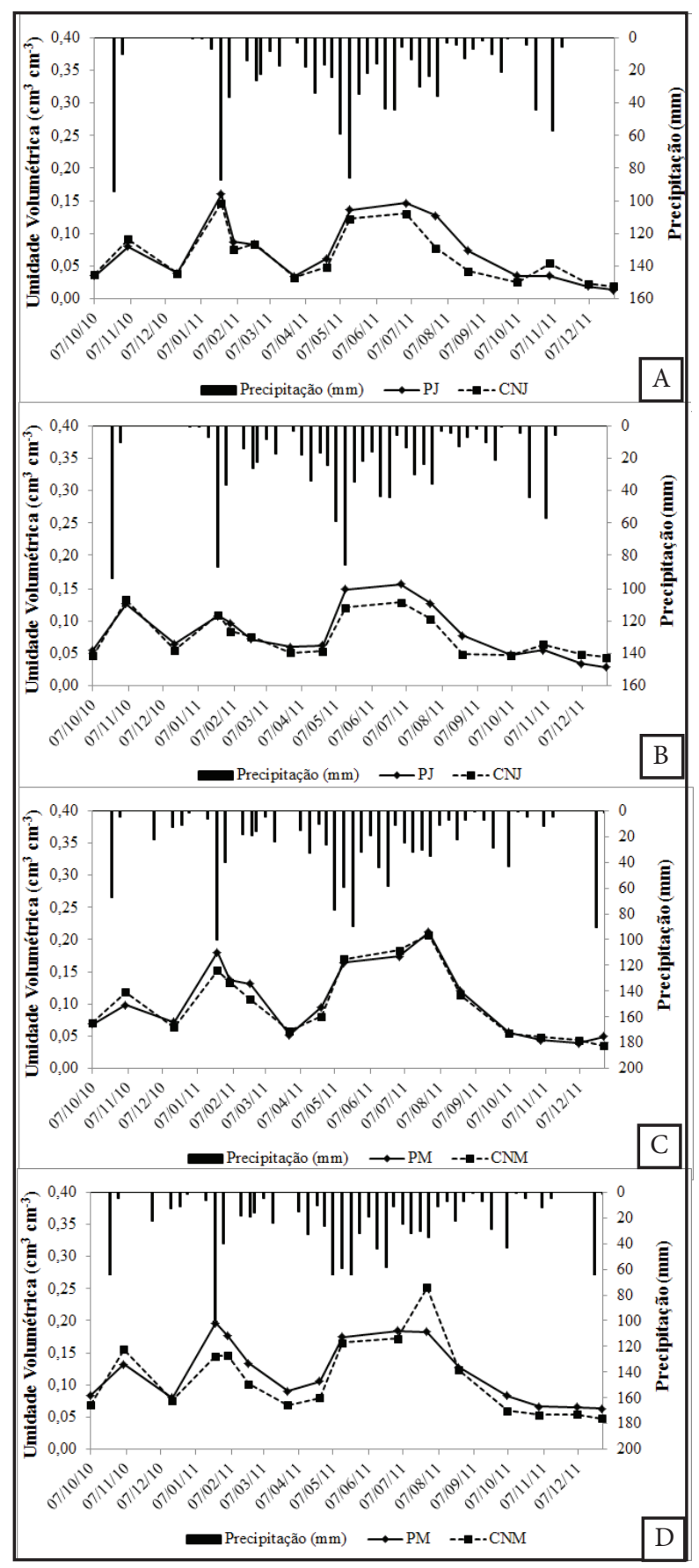

Figura 5 - Variação temporal da umidade do solo para as condições de PJ e CNJ nas profundidades 0,0-0,2 $\mathrm{m}$ (a) e 0,2-0,4 $\mathrm{m}$ (b) e nas áreas PM e CNM nas profundidades 0,0-0,2 m (c) e 0,2-0,4 m (d)

registrada no dia 02/07/11, como consequência da distribuição da umidade ao longo do perfil do solo, sendo função não do total precipitado, mas sim de uma melhor distribuição das precipitações antecedentes ao monitoramento.

Percebe-se que houve uma relação positiva entre os eventos de precipitação e a umidade na camada superficial do solo para todos os tratamentos, a qual sofre rápido aumento depois da chuva e diminui durante os períodos de estiagem (Figura 5). Comparando-se a umidade na camada superficial com a de $0,2-0,4 \mathrm{~m}$, verifica-se que para essa, a resposta à ocorrência

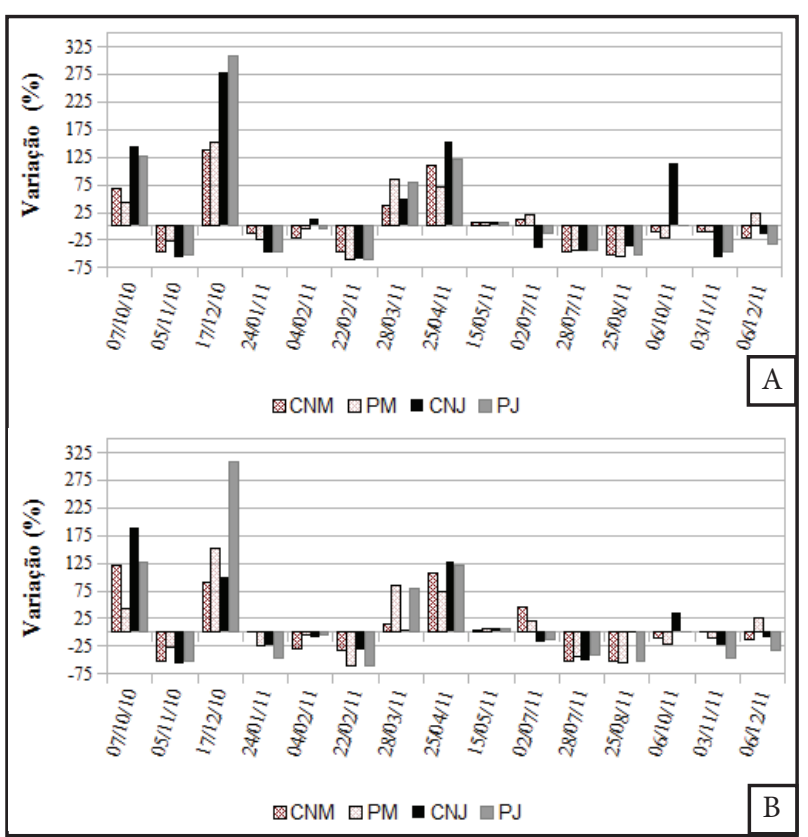

Figura 6 - Variação percentual da umidade do solo entre os monitoramentos consecutivos, nas profundidades $0,0-0,2 \mathrm{~m}$ (a) e $0,2-0,4 \mathrm{~m}$ (b)

de uma chuva é menos acentuada, embora o padrão de variação temporal em ambas as profundidades seja semelhante (Figura $5 \mathrm{a}-\mathrm{b}$; Figura $5 \mathrm{c}-\mathrm{d}$ ).

Esse comportamento foi semelhante ao descrito por Gao et al. (2011), e indica que as diferentes condições de cobertura e características dos solos da bacia induzem a variações espaciais da umidade, mas essa influência é menos expressiva sobre os padrões temporais da umidade do solo.

O teste de médias (Tabela 2) indica que para a maioria dos cenários de monitoramento os tratamentos não apresentam diferença significativa entre si. Gao et al. (2011) também não encontraram diferença significativa para a umidade na camada superficial de um solo sob cinco condições distintas de cobertura, semelhante a Chen et al. (2007), que encontraram baixas variações na umidade do solo na camada $0-20 \mathrm{~cm}$, também sob cinco condições de cobertura vegetal.

A figura 6 mostra que o percentual de variação da umidade em relação ao monitoramento antecedente é maior para as áreas situadas a jusante do ponto médio da bacia, mesmo quando a precipitação registrada nessa área é menor. A maior sensibilidade da umidade do solo nesses locais, em resposta aos eventos de chuva, é influenciada por sua composição granulométrica, onde o solo nos pontos de monitoramento apresentam maiores teores de areia em comparação aos locais a montante. Buckman e Brady (1979) destacam que a areia reduz a capacidade de retenção de água, devido ao grande espaço entre as partículas, favorecendo o rápido fluxo de água.

A figura 7 apresenta os box-plots relativos à umidade do solo para os diferentes tratamentos nas profundidades avaliadas. Os valores correspondem à média dos 16 monitoramentos realizados. As linhas extremas representam os valores máximos e mínimos observados, o $1^{\circ}$ e $3^{\circ}$ quartil delimitam a caixa, sendo o traço interno referente ao valor da mediana. 
Tabela 3 - Características físicas do solo nos pontos de monitoramento da área experimental, com distinção dos tratamentos ao qual pertence

\begin{tabular}{|c|c|c|c|c|c|c|c|c|c|c|c|c|c|}
\hline \multirow{2}{*}{ Trat. } & \multirow{2}{*}{ Ponto } & \multirow{2}{*}{$\begin{array}{l}\text { Prof. } \\
(\mathrm{cm})\end{array}$} & \multirow{2}{*}{$\frac{\text { Ds }}{\mathrm{Kg} \mathrm{dm}^{-3}}$} & \multirow{2}{*}{$\begin{array}{l}\text { Areia } \\
--- \\
\end{array}$} & \multirow{2}{*}{$\begin{array}{r}\text { Argila } \\
-\mathrm{g} \mathrm{Kg}^{-1}\end{array}$} & \multirow{2}{*}{$\begin{array}{l}\text { Silte } \\
---- \\
\end{array}$} & \multirow{2}{*}{ Trat. } & \multirow{2}{*}{ Ponto } & \multirow{2}{*}{$\begin{array}{l}\text { Prof. } \\
(\mathrm{cm})\end{array}$} & \multirow{2}{*}{$\frac{\text { Ds }}{\mathrm{Kg} \mathrm{dm}^{-3}}$} & \multirow{2}{*}{\multicolumn{3}{|c|}{ Areia Argila Silte }} \\
\hline & & & & & & & & & & & & & \\
\hline \multirow{28}{*}{ PM } & \multirow{4}{*}{ P1 } & $0-10$ & 1,49 & \multirow{2}{*}{ - 728,0 } & & & \multirow{4}{*}{ CNM } & \multirow{4}{*}{ P13 } & $0-10$ & 1,68 & \multirow[b]{2}{*}{623,2} & \multirow[b]{2}{*}{182,0} & \multirow[b]{2}{*}{194,8} \\
\hline & & $10-20$ & 1,54 & & 152,0 & 120,0 & & & $10-20$ & 1,66 & & & \\
\hline & & $20-30$ & 1,43 & & & & & & $20-30$ & 1,63 & & & \\
\hline & & $30-40$ & 1,61 & 708,0 & 191,0 & 94,4 & & & $30-40$ & 1,64 & 04,8 & $2 / 2,0$ & 223,2 \\
\hline & & $0-10$ & 1,48 & & 2176 & 1344 & & & $0-10$ & 1,46 & & & \\
\hline & & $10-20$ & 1,52 & 048,0 & $21 /, 0$ & 154,4 & & & $10-20$ & 1,54 & 088,0 & $1 / 7,0$ & 134,4 \\
\hline & $P 2$ & $20-30$ & 1,47 & 6080 & 2520 & 1400 & & P8 & $20-30$ & $*$ & * & * & * \\
\hline & & $30-40$ & 1,52 & 8,0 & $\angle 5 \angle, 0$ & 140,0 & & & $30-40$ & $*$ & $\pi$ & $\pi$ & 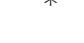 \\
\hline & & $0-10$ & 1,43 & 6280 & 2320 & 1400 & & & $0-10$ & 1,30 & & & \\
\hline & D3 & $10-20$ & 1,53 & 028,0 & $\angle 32,0$ & 140,0 & & p0 & $10-20$ & 1,36 & 784,0 & 88,8 & 127,2 \\
\hline & 13 & $20-30$ & 1,46 & & & & & 19 & $20-30$ & 1,35 & & & \\
\hline & & $30-40$ & 1,50 & 628,0 & 232,0 & 140,0 & & & $30-40$ & 1,25 & 34,0 & 92,4 & 73,6 \\
\hline & & $0-10$ & 1,30 & & & & & & $0-10$ & 1,37 & 242 & & \\
\hline & P4 & $10-20$ & 1,50 & 108,0 & $1 / 2,0$ & 120,0 & & 15 & $10-20$ & 1,36 & 124,2 & 112,0 & 103,8 \\
\hline & 14 & $20-30$ & 1,54 & 6080 & 2320 & 1600 & & 15 & $20-30$ & 1,37 & & & 1286 \\
\hline & & $30-40$ & 1,51 & $00 \delta, 0$ & $\angle J Z, 0$ & 100,0 & & & $30-40$ & 1,38 & 149,4 & $1 \angle 2,0$ & 128,0 \\
\hline & & $0-10$ & 1,51 & 6080 & 2320 & 160 & & & $0-10$ & 1,56 & 7352 & 112 1 & 1528 \\
\hline & P & $10-20$ & 1,55 & 0,0 & $\angle J \angle, 0$ & 100,0 & & 918 & $10-20$ & 1,59 & 135,2 & 112,0 & 152,0 \\
\hline & 15 & $20-30$ & 1,58 & 80 & 2720 & 1600 & & 18 & $20-30$ & 1,61 & 472 & 1220 & 1308 \\
\hline & & $30-40$ & 1,53 & 8,0 & $\angle / 2,0$ & 100,0 & & & $30-40$ & 1,62 & $4 /, 2$ & $1 \angle Z, 0$ & 150,8 \\
\hline & & $0-10$ & 1,45 & & 1076 & & & & $0-10$ & 1,54 & & & \\
\hline & & $10-20$ & 1,50 & $0 \angle 8,0$ & 191,0 & $1 / 4,4$ & & 10 & $10-20$ & 1,59 & 124,0 & 110,0 & 100,0 \\
\hline & 12 & $20-30$ & 1,48 & & 1076 & 104 & & 10 & $20-30$ & 1,54 & 40 & 824 & 1036 \\
\hline & & $30-40$ & 1,54 & 0,0 & (19, & 194,4 & & & $30-40$ & 1,63 & 814,0 & $8<, 4$ & 105,0 \\
\hline & & $0-10$ & 1,63 & 4058 & 2020 & 2122 & & & $0-10$ & 1,63 & 6478 & 1720 & 1802 \\
\hline & & $10-20$ & 1,62 & 493,0 & 292,0 & 212,2 & & . & $10-20$ & 1,64 & $04 /, 0$ & $1 / 2,0$ & 100,2 \\
\hline & 111 & $20-30$ & 1,65 & & & & & 114 & $20-30$ & 1,63 & & & \\
\hline & & $30-40$ & 1,62 & 6,2 & 392,0 & 171,8 & & & $30-40$ & 1,62 & 623,8 & 192,0 & 184,2 \\
\hline & & $0-10$ & 1,46 & 7080 & 2176 & 74.4 & CN J & & $0-10$ & 1,45 & 6544 & 1420 & 2036 \\
\hline & $\mathrm{D} 6$ & $10-20$ & 1,45 & 108,0 & $21 /, 0$ & 74,4 & & 11 & $10-20$ & 1,46 & 054,4 & 142,0 & 203,0 \\
\hline & 10 & $20-30$ & 1,43 & & 2580 & 940 & & 1210 & $20-30$ & 1,49 & 36 & & 2044 \\
\hline & & $30-40$ & 1,47 & 0 & 250,0 & 4,0 & & & $30-40$ & 1,50 & $J, 0$ & , & 204,4 \\
\hline C & & $0-10$ & 1,51 & 8 & 212 & 2182 & & & $0-10$ & 1,57 & & & 1550 \\
\hline & & $10-20$ & 1,55 & 569,8 & 212,0 & 218,2 & & & $10-20$ & 1,55 & 113,0 & 132,0 & 155,0 \\
\hline & I & $20-30$ & 1,57 & & 252 & & & 11 & $20-30$ & 1,55 & & & 16 \\
\hline & & $30-40$ & 1,59 & & $\angle 5 \angle, 0$ & 189,0 & & & $30-40$ & 1,57 & U5, 0 & 132,0 & 104,4 \\
\hline
\end{tabular}

PM - Pasto a Montante; PJ - Pasto a Jusante; CNM - Caatinga Natural a Montante e CNJ - Caatinga Natural a Jusante.

* profundidades não amostradas.

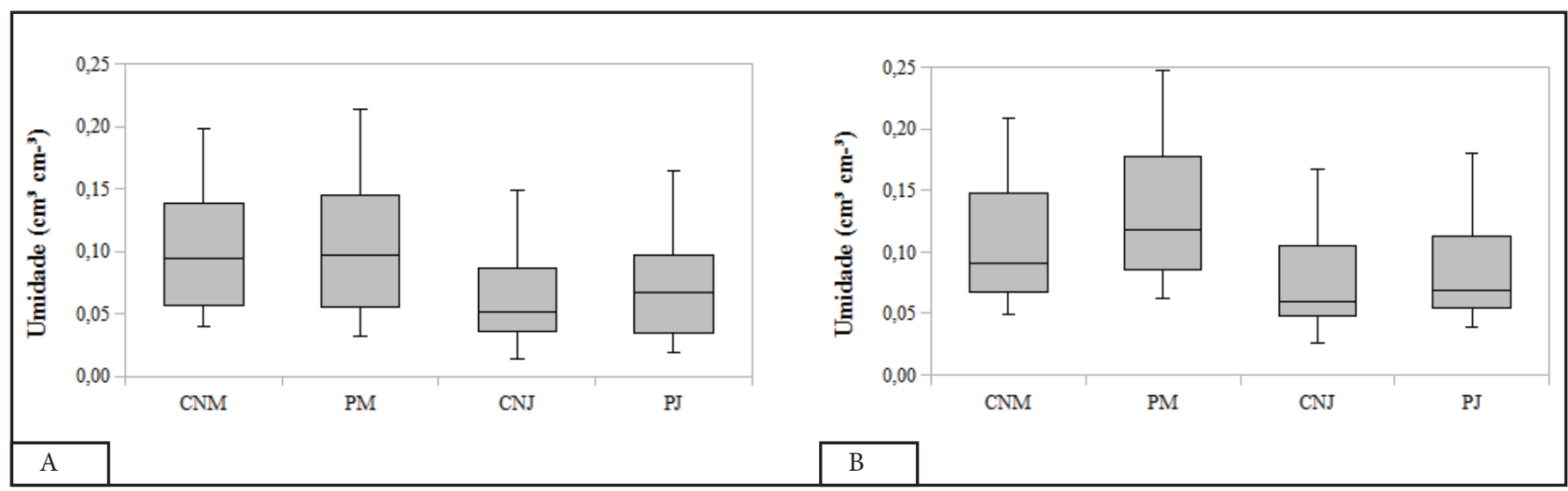

Figura 7 - Box-plot da umidade do solo na bacia do Jatobá, nos diferentes condições monitoradas, para as profundidades 0,0 - 0,2 m (a) e 0,2-0,4 m (b) 
Observa-se maior heterogeneidade temporal da umidade para as áreas situadas a montante da bacia, em ambas profundidades, sendo ainda possível verificar uma variabilidade um pouco maior para as áreas de pasto. A variabilidade dos dados é explicada pela variação sazonal da precipitação durante o período de monitoramento. Nunes (2010) comenta que esse fator é responsável pela maior parte da variabilidade da umidade em uma área de estudo, e cita ainda que a temperatura também pode explicar parte da variação dos registros de umidade, porém sendo mais evidente durante o período de estiagem. James et al. (2003), também avaliando a variabilidade da umidade em áreas sob diferentes condições de cobertura vegetal, enfatizam que o efeito dos diferentes tipos de vegetação sob a variabilidade do teor de água no solo são mais expressivos quando a disponibilidade das chuvas são mais escassas, a exemplo também do encontrado por Guo et al. (2002), e que diminuem quando esse recurso é abundante.

Considerando a variabilidade espacial da umidade dos solos entre os diferentes tratamentos para o período analisado, é possível verificar através da avaliação da evolução mensal dos coeficientes de variação (Figura 8), que os desvios tendem ser mais expressivos no período de menor ocorrência de chuvas, e que esses diminuem, acusando uma maior homogeneidade entre os diferentes tratamentos monitorados, quando do período de ocorrência das precipitações e consequente maiores registros de umidade. Ainda avaliando o comportamento, para a camada $0,2-0,4 \mathrm{~m}$, esse apresenta menores coeficientes de variação,

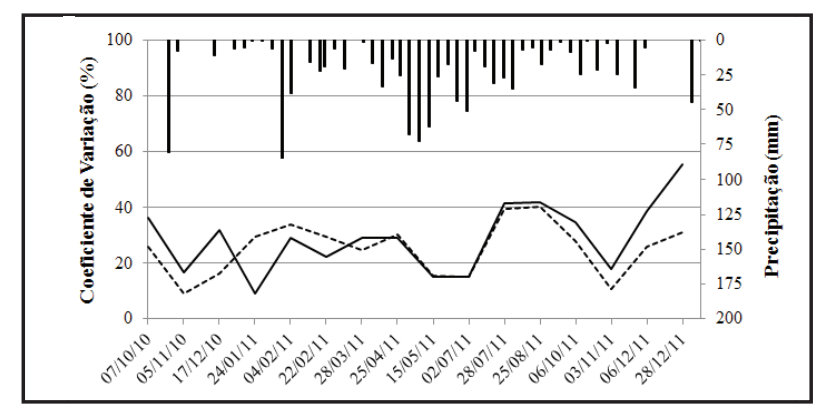

Figura 8 - Evolução dos coeficientes de variação dos valores da umidade média do solo para as diferentes condições de cobertura e localização monitoradas

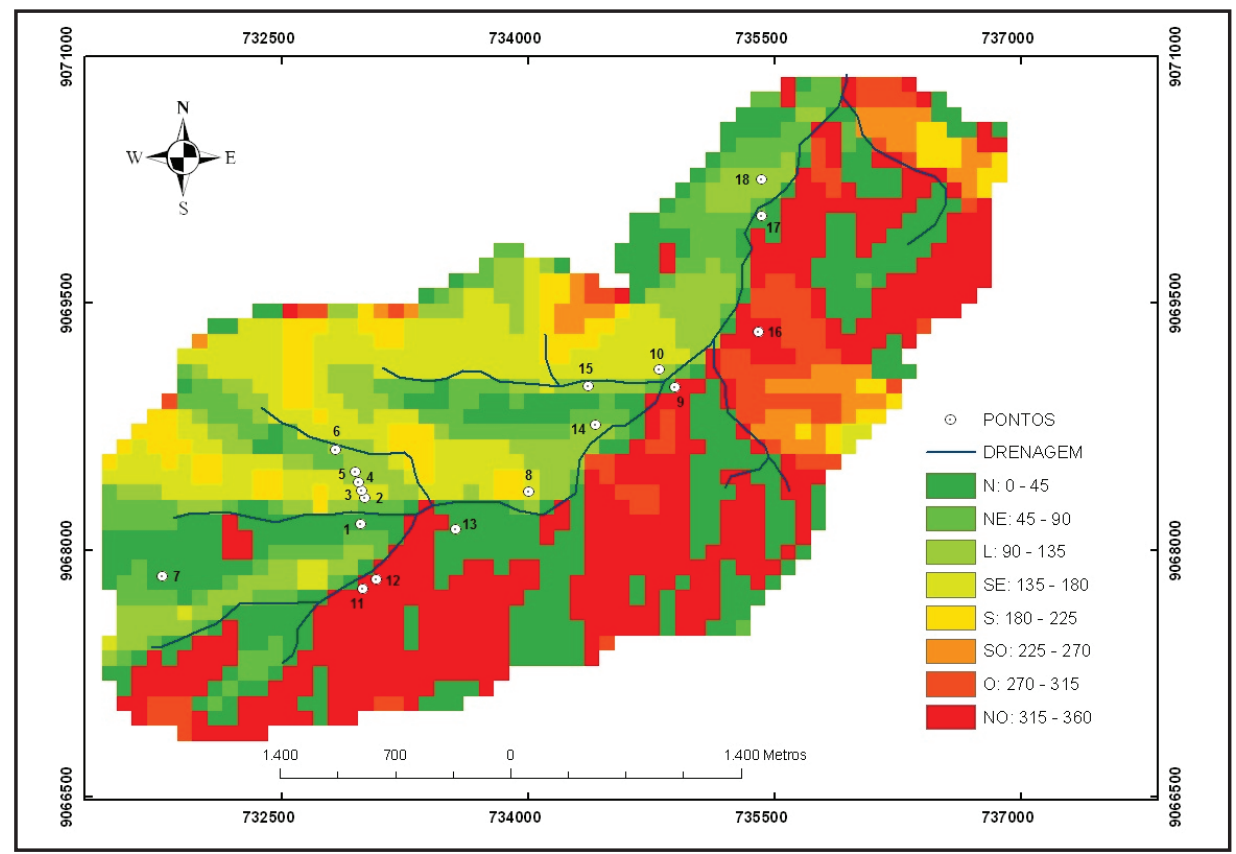

Figura 9 - Mapa de orientação de vertentes da bacia hidrográfica do Jatobá com discretização da rede de drenagem e localização dos pontos de monitoramento da umidade do solo

Tabela 4 - Faixa de valores dos ângulos para confecção da rosa dos ventos referente as disposições diferenciadas do terreno; porção da área da bacia exposta a cada direção e pontos localizados em cada vertente

\begin{tabular}{ccccc}
\hline Direção da vertente & Graus & Área da bacia $\left(\mathbf{K m}^{2}\right)$ & \% da área total & Pontos \\
\hline Norte - N & $1-45$ & 3,037 & 24,4 & P1; P7; P13; P17; \\
Nordeste - NE & $46-90$ & 1,239 & 10,0 & P6 \\
Leste - L & $91-135$ & 1,247 & 10,0 & P4; P5; P14; P15; P18; \\
Sudeste - SE & $136-180$ & 1,604 & 12,9 & P2; P3; P8; P10 \\
Sul - S & $181-225$ & 0,721 & 5,8 & \\
Sudoeste - SO & $226-270$ & 0,421 & 3,4 & \\
Oeste - O & $271-315$ & 0,729 & 5,9 & \\
Noroeste - NO & $316-360$ & 3,442 & 27,7 & P9; P11; P12: P16 \\
\hline
\end{tabular}


Melo e Montenegro.: Dinâmica temporal da umidade do solo em uma bacia hidrográfica no semiárido Pernambucano

Tabela 5 - Umidade volumétrica média nas áreas da bacia hidrográfica do Jatobá, sob mesma condição de cobertura vegetal e diferentes posições de vertente, para as profundidades de $0,0-0,2 \mathrm{~m}$ e $0,2-0,4 \mathrm{~m}$

\begin{tabular}{|c|c|c|c|c|c|c|c|c|}
\hline \multirow{3}{*}{ Data } & \multicolumn{8}{|c|}{ Umidade Volumétrica Média $\left(\mathrm{cm}^{3} \mathrm{~cm}^{-3}\right)$} \\
\hline & \multicolumn{4}{|c|}{$0,0-0,2 \mathrm{~m}$} & \multicolumn{4}{|c|}{$0,2-0,4 \mathrm{~m}$} \\
\hline & CNS & $C N N$ & $P S$ & $P N$ & CNS & $C N N$ & $P S$ & $P N$ \\
\hline $07 / 10 / 10$ & $0,046 \mathrm{a}$ & $0,054 \mathrm{a}$ & $0,051 \mathrm{a}$ & $0,067 \mathrm{a}$ & $0,057 \mathrm{a}$ & $0,056 \mathrm{a}$ & $0,073 \mathrm{a}$ & 0,079 ; \\
\hline 05/11/10 & $0,092 \mathrm{a}$ & $0,107 \mathrm{a}$ & 0,089 a & $0,097 \mathrm{a}$ & $0,134 \mathrm{a}$ & $0,146 \mathrm{a}$ & $0,133 \mathrm{a}$ & 0,128 ; \\
\hline $17 / 12 / 10$ & $0,045 \mathrm{a}$ & $0,052 \mathrm{a}$ & $0,051 \mathrm{a}$ & $0,075 \mathrm{a}$ & $0,051 \mathrm{a}$ & 0,069 a & $0,073 \mathrm{a}$ & 0,078 ; \\
\hline $24 / 01 / 11$ & $0,154 \mathrm{a}$ & $0,147 \mathrm{a}$ & 0,166 a & 0,186 a & $0,127 \mathrm{a}$ & 0,123 a & $0,182 \mathrm{a}$ & 0,152 ; \\
\hline $04 / 02 / 11$ & $0,087 \mathrm{a}$ & $0,106 \mathrm{a}$ & 0,119 a & $0,120 \mathrm{a}$ & $0,090 \mathrm{a}$ & $0,119 \mathrm{a}$ & $0,163 \mathrm{a}$ & 0,137 ; \\
\hline $22 / 02 / 11$ & $0,087 \mathrm{a}$ & $0,097 \mathrm{a}$ & $0,115 \mathrm{a}$ & $0,112 \mathrm{a}$ & $0,080 \mathrm{a}$ & $0,090 \mathrm{a}$ & 0,119 a & c \\
\hline $28 / 03 / 11$ & $0,038 \mathrm{a}$ & $0,046 \mathrm{a}$ & $0,049 \mathrm{a}$ & $0,038 \mathrm{a}$ & $0,050 \mathrm{a}$ & $0,063 \mathrm{a}$ & $0,084 \mathrm{a}$ & 0,078 ; \\
\hline $25 / 04 / 11$ & $0,055 \mathrm{a}$ & $0,065 \mathrm{a}$ & $0,076 \mathrm{a}$ & $0,096 \mathrm{a}$ & $0,050 \mathrm{a}$ & $0,071 \mathrm{a}$ & $0,095 \mathrm{a}$ & c, \\
\hline $15 / 05 / 11$ & $0,115 \mathrm{a}$ & $0,154 \mathrm{a}$ & $0,146 \mathrm{a}$ & $0,168 \mathrm{a}$ & $0,106 \mathrm{a}$ & $0,154 \mathrm{a}$ & $0,170 \mathrm{a}$ & 0,162 ; \\
\hline 02/07/11 & $0,123 \mathrm{a}$ & $0,165 \mathrm{a}$ & $0,157 \mathrm{a}$ & $0,177 \mathrm{a}$ & $0,116 \mathrm{a}$ & $0,160 \mathrm{a}$ & $0,181 \mathrm{a}$ & c \\
\hline $28 / 07 / 11$ & 0,064 a & $0,161 \mathrm{a}$ & $0,167 \mathrm{a}$ & $0,205 \mathrm{a}$ & $0,096 \mathrm{a}$ & $0,195 \mathrm{a}$ & $0,165 \mathrm{a}$ & 0,167 ; \\
\hline $25 / 08 / 11$ & $0,043 \mathrm{a}$ & $0,085 \mathrm{a}$ & $0,101 \mathrm{a}$ & $0,109 \mathrm{a}$ & $0,037 \mathrm{a}$ & 0,098 a & $0,114 \mathrm{a}$ & 0,110 ; \\
\hline $06 / 10 / 11$ & $0,026 \mathrm{a}$ & $0,043 \mathrm{a}$ & $0,047 \mathrm{a}$ & $0,051 \mathrm{a}$ & $0,048 \mathrm{a}$ & $0,055 \mathrm{a}$ & $0,072 \mathrm{a}$ & 0,073 ; \\
\hline 03/11/11 & $0,037 \mathrm{a}$ & $0,058 \mathrm{a}$ & $0,040 \mathrm{a}$ & $0,042 \mathrm{a}$ & $0,052 \mathrm{a}$ & $0,063 \mathrm{a}$ & $0,064 \mathrm{a}$ & 0,062 \\
\hline $06 / 12 / 11$ & $0,024 \mathrm{a}$ & $0,036 \mathrm{a}$ & $0,029 \mathrm{a}$ & $0,037 \mathrm{a}$ & $0,045 \mathrm{a}$ & $0,054 \mathrm{a}$ & $0,052 \mathrm{a}$ & 0,062 ؛ \\
\hline $28 / 12 / 11$ & $0,018 \mathrm{a}$ & $0,030 \mathrm{a}$ & $0,029 \mathrm{a}$ & $0,049 \mathrm{a}$ & $0,039 \mathrm{a}$ & $0,049 \mathrm{a}$ & $0,046 \mathrm{a}$ & 0,063 ; \\
\hline
\end{tabular}

o que significa que os desvios entre os tratamentos avaliados são menores nessa profundidade, e que o comportamento geral também sugere que quanto menor for a precipitação, maiores serão as diferenças de umidade nas diferentes condições de uso do solo. Esse comportamento está em acordo com o encontrado por Nunes (2010), que avaliando o comportamento temporal do coeficiente de variação entre médias da umidade do solo sob seis condições de coberturas diferentes, encontrou uma forte relação entre a ocorrência de chuvas e redução dos valores, chegando a superar $100 \%$ em um período de verão.

Na figura 9 é apresentado o mapa de orientação de vertentes da bacia hidrográfica do Jatobá com a disposição dos pontos de monitoramento, sendo apresentada na tabela 4 , a porção da área da bacia exposta a cada situação de orientação. É possível verificar que $62,0 \%$ da área total da bacia do Jatobá esta voltada para as posições nordeste, noroeste e principalmente norte, que recebem maior incidência dos raios solares.

Mello (2009) relata que nas vertentes que recebem maior insolação, há um aumento na temperatura e, consequente, aumento da evapotranspiração, o que causa redução no conteúdo de água do solo. Nas vertentes que recebem menor insolação, as temperaturas são menores e a umidade é maior. Dessa forma, o comportamento esperado para essas áreas da bacia do Jatobá voltadas à nordeste, noroeste e norte, é que os valores de umidade monitorada fossem menores que aqueles registrados para a mesma condição de superfície situados em faces do terreno voltadas para o sul. Porém, observando os valores umidade média (Tabela 5), não é possível perceber esse padrão para a bacia do Jatobá. A explicação para esse comportamento pode estar relacionada com a latitude do local, com reduzidas variações de radiação para diferentes orientações. Adicionalmente, deve-se mencionar o fato de que esses locais de monitoramento, situados na porção que recebe maior incidência de raios solares, estão localizados na parte baixa de longas vertentes e, que em função da presença de camadas de impedimento, evidenciadas durante a instalação da rede de monitoramento, faz com que, em adição ao fluxo vertical da água, surja um fluxo lateral subsuperficial morro abaixo, chamado de interfluxo, paralelo às camadas de menor permeabilidade e resultante da combinação das forças de gravidade e do gradiente de pressão (HUGGINS, 1979).

Paiva et al. (1998), analisando o armazenamento e a disponibilidade de água ao longo do tempo, em uma topossequência de solos de tabuleiro do Estado da Bahia, encontraram maior disponibilidade de água no terço inferior da vertente. Souza et al. (2002), em um estudo com a mesma finalidade, concluíram que nos períodos mais chuvosos a presença de horizontes coesos subsuperficiais nos solos de tabuleiro localizados nas partes mais altas do declive restringe o fluxo vertical da água, ocorrendo a formação de lençol freático suspenso acima dos horizontes coesos e favorecendo o interfluxo no sentido do declive, em direção aos solos localizados nas partes mais baixas do relevo. Ávila, Mello e Silva (2010), estudando o comportamento temporal da umidade em áreas de pastagem, mata atlântica e várzea, verificaram que o processo de redução do conteúdo de água no solo na várzea é retardado no tempo em razão do recebimento dos fluxos provenientes de cotas superiores e da ocorrência da ascensão capilar de água do lençol freático, resultando num solo mais provido de água.

As médias foram comparadas para condições de cobertura semelhantes e diferentes posições de orientação de vertentes. Médias seguidas de mesma letra na linha indicam que não houve diferença significativa entre os tratamentos pelo teste de Tukey ao nível de 5\%. CNS - Cobertura Natural de Caatinga nas vertentes à Sul; CNN - Cobertura Natural de Caatinga nas vertentes à Norte; PS - Pasto nas vertentes à Sul e PN - Pasto à Norte. 
Tabela 6 - Efetividade relativa percentual da água no solo para os diferentes tratamentos e profundidades avaliadas

\begin{tabular}{|c|c|c|c|c|c|c|}
\hline \multirow{2}{*}{ Tratamentos } & $>1$ & $0,75-1$ & $0,5-0,75$ & $0,25-0,5$ & $0-0,25$ & $<0$ \\
\hline & \multicolumn{6}{|c|}{$0,0-0,2 \mathrm{~m}$} \\
\hline CNM & 0,00 & 0,00 & 6,25 & 18,75 & 25,00 & 50,00 \\
\hline $\mathbf{P M}$ & 0,00 & 0,00 & 0,00 & 18,75 & 37,50 & 43,75 \\
\hline $\mathrm{CNJ}$ & 0,00 & 0,00 & 0,00 & 6,25 & 25,00 & 68,75 \\
\hline PJ & 0,00 & 0,00 & 0,00 & 25,00 & 31,25 & 43,75 \\
\hline \multicolumn{7}{|c|}{$0,2-0,4 m$} \\
\hline CNM & 0,00 & 0,00 & 0,00 & 12,50 & 87,50 & 0,00 \\
\hline PM & 0,00 & 0,00 & 6,25 & 18,75 & 37,50 & 37,50 \\
\hline $\mathrm{CNJ}$ & 0,00 & 0,00 & 0,00 & 6,25 & 62,50 & 31,25 \\
\hline PJ & 0,00 & 0,00 & 0,00 & 31,25 & 43,75 & 25,00 \\
\hline
\end{tabular}

\section{Efetividade da água do solo}

Observa-se na tabela 6 que em $94 \%$ dos monitoramentos realizados, a efetividade do conteúdo médio de água do solo em todos tratamentos apresentou-se de "Baixa" a "Não Efetiva", de acordo com o critério proposto por Chen et al. (2007), sendo apenas um pequeno percentual de $6 \%$ dos monitoramentos realizados com efetividade do valor médio de água do solo sendo de "Moderada" a "Alta", encontrada para a condição de CNM (em 0,0-0,2 m) e para PM (na profundidade 0,2-0,4 m).

A distinção da classe de efetividade do conteúdo de água no solo está condicionada à proximidade entre a ocorrência das chuvas e ao período de monitoramento, sendo a condição de "Extremamente Efetivo" e de "Alta Efetividade" relacionadas à ocorrência de uma infiltração de água do solo muito próxima à data de avaliação. Isso explica o fato de nenhuma dessas classes serem encontradas para os monitoramentos, já que no momento de todas as avaliações as chuvas já haviam ocorrido e a água já havia sido redistribuída ao longo do perfil do solo. No trabalho de Santos, Montenegro e Silva (2011), valores de afetividade acima de 0,75 foram encontrados, já que foi utilizado na determinação da umidade sondas do tipo TDR, que ligadas a um datalogger, permitiu um monitoramento em escala diária da variação da umidade do solo, podendo dessa forma serem encontradas condições de saturação do solo ou umidades próximas à capacidade de campo.

\section{CONCLUSÕES}

1. A umidade do solo na bacia hidrográfica do Jatobá é maior na porção à montante do ponto médio desta.

2. As diferentes condições de cobertura vegetal e características dos solos da bacia induzem a variações espaciais da umidade, sendo essa influência menos expressiva sobre seus padrões temporais.

3. A variabilidade entre os valores médios da umidade do solo para os tratamentos avaliados é menor durante o período das chuvas, bem como na profundidade $0,2-0,4 \mathrm{~m}$.
4. A efetividade da água do solo foi baixa durante a maior parte do monitoramento realizado.

5. A análise da influência da orientação de vertentes no conteúdo de água do solo não permitiu estabelecer um padrão característico para a bacia do Jatobá.

6. Recomenda-se estabelecimento de zonas de proteção nas regiões de maior umidade, de modo a incrementar o gerenciamento ambiental dabacia, e de suas nascentes.

\section{REFERÊNCIAS}

ANDRADE, A. R. S.; JADOSKI, S. O.; GUERRA, H. C.; GUERRINI, I. A. Influência do tempo de contagem na determinação da densidade de nêutrons. Revista Brasileira de Engenharia Agricola e Ambiental, v. 5, n. 3, p. 411-415, set./dez. 2001.

ÁVILA, L. F.; MELLO, C. R.; MELLO, J. M.; SILVA, A. M. Padrão Espaço-Temporal da Umidade Volumétrica do Solo em uma Bacia Hidrográfica com Predominância de Latossolos. Revista Brasileira de Ciência do Solo, v.35, n. 5, p. 1801-1810, 2011.

ÁVILA, L. F.; MELLO, C. R.; SILVA, A. M. Estabilidade Temporal do Conteúdo de Água em três condições de uso do solo, em uma bacia hidrográfica da região da Serra da Mantiqueira, MG. Revista Brasileira de Ciência do Solo, v. 34, n. 6, p. 2001-2009, nov./dec. 2010.

BUCKMAN, H. O.; BRADY, N. C. Natureza e propriedade dos solos. 5.ed. Trad. Figueiredo Filho, A. B. N. Rio de Janeiro: Biblioteca Universitária Freitas Bastos, 1979.

CARLESSO, R.; ZIMMERMANN, F. L. Água no solo: parâmetros para dimensionamento de sistemas de irrigação. Santa Maria: Ed. UFSM, 2000. (Caderno Didático, nº 3).

CARVAlHO, B. C.; OLIVEIRA, D. Dados morfométricos extraídos a partir de modelo digital de terreno hidrologicamente corrigido como subsídio a análise ambiental. Disponível 
em: <http://www.selper-mexico.org.mx/XT\%20PDF/ HIDROLOGIA/HIDRO-03.pdf>. Acesso em: 19 fev. 2013.

CHEN, L.; HUANG, Z.; GONG, J.; FU, B.; HUANG, Y. The effect of land cover/vegetation on soil water dynamic in the hilly area of the loess plateau, China. Catena, v. 70, n. 2, p. 200208, July 2007.

CORREA, M. M.; RIBEIRO, M. R. Levantamento detalhado de solos da fazenda Nossa Senhora do Rosario (Pesqueira - PE). Relatório Técnico. Recife: UFRPE/UFPE/CNPq/BNB, 2001.

EMBRAPA - EMPRESA BRASILEIRA DE PESQUISA AGROPECUÁRIA. Manual de métodos de análises de solo. 2. ed. Rio de Janeiro: Ministério da Agricultura e do Abastecimento, 1997.

GAO, X.; WU, P.; ZHAO, X.; SHI, Y.; WANG, J. Estimating spatial mean soil water contents of sloping jujube orchards using temporal stability. Agricultural Water Management, v. 102, n. 1, p. 66-73, Dec. 2011.

GÓMEZ-PLAZA, A.; ALVAREZ-ROGEL, J.; ALBALADEJO, J.; CASTILLO, V. M. 'Spatial patterns and temporal stability of soil moisture across a range of scales in semi-arid environment', Hydrological Processes, v. 14, n. 7, p. 1261-1277, 2000.

GUO, D.; MOU, P.; JONES, R. H.; MITCHELL, R. J. Temporal changes in spatial patterns of soil moisture following disturbance: an experimental approach. Journal of Ecology, v. 90, n. 2, p. 338-347, Apr. 2002.

HU, W.; SI, B. C. Can soil water measurements at a certain depth be used to estimate mean soil water content of a soil profile at a point or at a hillslope scale?, Journal of Hydrology, v. 516, p. 67-75, Aug. 2014

HUGGINS, L. F. Small watershed hydrology. Lafayette: Purdue University/Agricultural Engineering Department, 1979.

ILLSTON, B. G.; BASARA, J. B.; CRAWFORD, K. C. Seasonal to interanual variations of soil moisture measured in Oklahoma. International Journal of Climatology, v. 24, n. 15, p. 1883-1896, Dec. 2004.

JAMES, S. E.; PÄRTEL, M.; WILSON, S. D.; PELTZER, D. A. 'Temporal heterogeneity of soil in grassland and forest'. Journal of Ecology, v. 91, n. 2, p. 234-239, Apr. 2003.

JOSHI, C.; MOHANTY, B. P.; JACOBS, J. M.; INES, A. V. M. Spatio temporal analyses of soil moisture from point to footprint scale in two different hydroclimatic regions. Water Resources Research, v. 47, n. 1, p. 1-20, 2011.

MEDEIROS, J. D.; CLARKE, J. A. G. Variabilidade espacial do conteúdo de água no solo numa pequena bacia rural: Análise geoestatística. Revista Brasileira de Recursos Hídricos, v. 12, n. 1, p. 43-52, já./mar. 2007.
MEDEIROS, J. D. F. Variabilidade Espacial do Conteúdo de Água no Solo na Bacia do Arroio Donato - RS. 2004. Tese (Doutorado) - Universidade Federal do Rio Grande do Sul, Porto Alegre, 2004.

MELLO, T. F. Estrutura da vegetação, cobertura florestal e preferências de uso da paisagem associadas a vertentes: as quase florestas de São Luiz do Paraitinga. 2009. 76 p. Dissertação (Mestrado) - Instituto de Biociências, Universidade de São Paulo, São Paulo, 2009.

MONTE-MOR, R. C. A.; PALMIER, L. R.; ANDRADE PINTO, E. J.; LIMA, J. E. S. Estabilidade Temporal da Distribuição Espacial da Umidade do Solo em uma Bacia Intermitente no Semiárido de Minas Gerais. Revista Brasileira de Recursos Hídricos, v. 17, n. 3, p. 101-113, jul./set. 2012.

MONTENEGRO, A. A. A.; RAGAB, R. Hydrological response of a Brazilian semi-arid catchment to different land use and climate change scenarios: a modelling study. Hydrological Processes, v. 24, n. 19, p. 2705-2723, Sept. 2010.

NUNES, A. Análise Comparativa da Humidade do Solo Sob Diferentes Usos e Cobertos Vegetais. In: SEMINÁRIO LATINO-AMERICANO DE GEOGRAFIA FÍSICA, 6.; SEMINÁRIO IBERO-AMERICANO DE GEOGRAFIA FÍSICA, 2., Coimbra, 2010. Anais... Coimbra: Universidade de Coimbra, 2010.PAIVA, A. Q.; SOUZA, L. S.; RIBEIRO, A. C.; COSTA, L. M. Disponibilidade de água em uma toposseqüência de solos de tabuleiro do estado da Bahia e sua relação com indicadores do crescimento da laranjeira. Revista Brasileira de Ciência do Solo, v. 22, n. 3, p. 367-377, jul./set. 1998.

PAN, Y. X; WANG, X. P; JIA, R. L.; CHEN, Y. W.; HE, M. Z. Spatial variability of surface soil moisture content in a revegetated desert area in Shapotou, Nothern China. Journal of Arid Enviroments, v. 72, n. 9, p. 1975-1683, Sept. 2008.

PORPORATO, A.; D'ORICO, P.; LAIO, F.; RIDOLFI, L.; RODRIGUEZ-ITURBE, I. Ecohydrology of water-controlled ecosystems. Advances in Water Resources, v. 25, p. 1335-1348, 2002.

QIU, Y.; FU, B.; WANG, J.; CHEN, L.; MENG, Q.; ZHANG, Y. Spatial prediction of soil moisture content using multiple-linear regressions in a gully catchment of the Loess Plateau, China. Journal of Arid Environments, v. 74, n. 2, p. 208-220, Feb. 2010.

QIU, Y.; FU, B. J.; WANG, J.; CHEN, L. D. Soil moisture variation in relation to topography and land use in a hillslope catchment of the Loess Plateau, China. Journal of Hydrology, v. 240, n. 3-4, p. 243-263, Jan. 2001.

ROBINSON, D. A.; CAMPBELL, C. S.; HOPMANS, J. W.; HORNBUCKLE, B. K.; JONES, S. B.; KNIGHT, R.; OGDEN, F.; SELKER, J.; WENDROTH, O. Soil moisture measurement for ecological and hydrological watershed-scale observatories: a review. Vadose Zone Journal, v. 7, p. 358-389, 2008. 
ROSSATO, L.; ALVALÁ, R. C. S.; TOMASELLA, J. Variação espaço-temporal da umidade do solo no brasil: análise das condições médias para o período de 1971-1990. Revista Brasileira de Meteorologia, v. 19, n. 2, p. 113-122, 2004.

SANTOS, T. E. M. Dinâmica Espacial e Temporal da Umidade do Solo em Bacia Experimental do Semiárido Pernambucano. 2010. 68 p. Tese (Doutorado em Ciência do Solo) - Universidade Federal Rural de Pernambuco, Recife, 2010.

SANTOS, T. E. M.; MONTENEGRO, A. A. A.; SILVA, D. D. Umidade do solo no semiárido pernambucano usando-se reflectometria no domínio do tempo (TDR). Revista Brasileira de Engenharia Agricola e Ambiental, v. 15, n. 7, p. 670-679, jul. 2011

SANTOS, T. E. M.; MONTENEGRO, A. A. A; SILVA, V. P.; SILVA JUNIOR, V. P.; MONTENEGRO, S. M. G. L. Erosão hídrica e perda de carbono orgânico em diferentes tipos de cobertura de solo no semi-árido, em condições de chuva simulada. Revista Brasileira de Recursos Hídricos, v. 13, n. 2, p. 1-15, apr./ jun. 2008.

SANTOS, T. E. M.; SILVA, D. D.; MONTENEGRO, A. A. A. Temporal Variability of Soil Water Content Under Different Surface Conditions in the Semiarid Region of the Pernambuco State. Revista Brasileira de Ciência do Solo, v. 34, n. 5, p. 1733-1741, sept./oct. 2010.

SILVA, A. N.; MONTEnEGRO, A. A. A.; MOURA, G. B. A. Efeito das mudanças climáticas no armazenamento de água em diferentes solos do agreste pernambucano. In: SIMPÓSIO DE RECURSOS HÍDRICOS DO NORDESTE, 9., 2008. Salvador. Anais... Salvador: ABRH, 2008. CD-ROM.

SOUZA, L. S.; PAIVA, A. Q.; SOUZA, L. D.; COGO, N. P. Água no solo influenciada pela posição na paisagem, em uma topossequência de solos de tabuleiro do Estado da Bahia. Revista Brasileira de Ciência do Solo, v. 26, n. 4, p. 843-855, 2002.

TAKYU, M.; AIBA, S.; KITAYAMA, K. Effects of topography on tropical lower montane forests under different geological conditions on Mount Kinabalu, Borneo. Plant Ecology, v. 159, n. 1, p. 35-49, Mar. 2002.

TINLEY, K. L. The influence of soil moisture balance on ecosystem patterns in south Africa. In: HUNTLEY, B. J.; WALKER, B. H. (Ed.). Ecology of Tropical Savannas. Berlin: Springer-Verlag, 1982. p. 175-192.

VEREECKEN H.; HUISMAN J. A.; PACHEPSKY Y.; MONTZKA C.; VAN DER KRUK J.; BOGENA H.; WEIHERMÜLLER L.; HERBST M.; MARTINEZ G.; VANDERBORGHT J. On the spatio-temporal dynamics of soil moisture at the field scale. Journal of Hydrology, v. 516, p. 76-96, 2014
WILCOX, B P.; TURNBULL, L.; YOUNG, M. H.; WILLIAMS, C J.; RAVI, S.; SEYFRIED, M. S.; BOWLING, D. R.; SCOTTT, R. L.; GERMINO, M. J.; CALDWELL, T. G.; WAINWRIGHT, J. Invasion of shrublands by exotic grasses: ecohydrological consequences in cold versus warm deserts. Ecohydrology, v. 5, p. $160-173,2012$.

YANG, L.; WEI, W.; CHEN, L.; JIA, F.; MO, B. Spatial variations of shallow and deep soil moisture in the semi-arid Loess Plateau, China. Hydrology and Earth System Sciences, v. 16, p. 3199-3217, 2012. 